\title{
The need and demand for renal replacement therapy in ethnic minorities in England
}

\author{
P J Roderick, V S Raleigh, L Hallam, N P Mallick
}

\begin{abstract}
Study objective - The study aimed to determine the relative risk of being accepted for renal replacement treatment of black and Asian populations compared with whites in relation to age, sex, and underlying cause. The implications for population need for renal replacement therapy in these populations and for the development of renal services were also considered.
\end{abstract}

Design/setting - This was a cross sectional retrospective survey of all patients accepted for renal replacement treatment in renal units in England in 1991 and 1992.

Patients - These comprised all 5901 patients resident in England with endstage renal failure who had been accepted for renal replacement therapy in renal units in England and whose ethnic category was available from the units. Patients were categorised as white, Asian, black, or other. Population denominators for the ethnic populations were taken from the 1991 census. The census categories Indian, Pakistani, and Bangladeshi were aggregated to form the denominator for Asian patients, and black Caribbeans, black Africans, and black others were aggregated to form the denominator for black patients.

Department of Public Health Medicine, University of Southampton, Level B South Academic Block, Southampton General hospital, Tremona Road, Southampton SO16 6YD P J Roderick L Hallam

Institute of Public Health, University of Surrey, Guildford, Surrey

V S Raleigh

Department of Nephrology, Manchester Royal Infirmary,

Manchester

N P Mallick

Correspondence to: Dr Paul Roderick Senior Lecturer in Public Health Medicine, University of Southampton Level B South Academic Block, Southampton General Hospital, Tremona Road, Southampton SO16 6YD. Accepted for publication January 1996
Conclusion - Acceptance rates for renal replacement treatment are increased sig- nificantly in Asian and black populations. Although data inaccuracies and access factors may contribute to these findings, the main reason is probably the higher incidence of end-stage renal failure. This in turn is due to the greater prevalence of underlying diseases such as non-insulin dependent diabetes but possibly also increased susceptibility of developing nethropathy. The main implication is that these populations age demand for renal replacement treatment will increase. This will have an impact nationally but will be particularly apparent in areas with large ethnic minority populations. Future planning must take these factors into account and should include strategies for preventing chronic renal failure, especially that due to non-insulin dependent diabetes and hypertension. The data could not determine the extent to which population need was being met; further studies are required to estimate the incidence of endstage renal failue in ethnic minority populations.

\section{(f Epidemiol Community Health 1996;50:334-339)}

Although end-stage renal failure is relatively uncommon, treatment by renal replacement therapy (dialysis or transplantation) is complex, costly, and has to be given lifelong. Without treatment patients die. Provision in the UK has expanded significantly in the past decade. Health authorities are responsible for assessing the health needs of their populations and for ensuring that effective services are available to meet them. ${ }^{1}$ The population need for renal replacement therapy in the UK has been estimated in population based studies, ${ }^{2-4}$ and a national estimate of 80 new patients under age 80 to be accepted per year per million population has been established. ${ }^{5}$ These studies were undertaken in areas in which the ethnic minority population was still young, or overall was small.

There is, however, growing evidence to show that black and Asian (those originating from the Indian subcontinent) people have an increased need and demand for renal replacement therapy. The London Implementation Group Review in the Thames health regions found a threefold higher crude acceptance rate for new black and Asian patients compared with whites. ${ }^{67}$

We present data from the national review of renal services in England, the first time a national dataset on ethnicity and uptake of health 
Table 1 Average annual acceptance rates per million population in England in relation to ethnic group 1991-92.

\begin{tabular}{|c|c|c|c|c|c|c|}
\hline \multirow[t]{2}{*}{ Age group (y) } & \multicolumn{2}{|l|}{ White } & \multicolumn{2}{|l|}{ Asian } & \multicolumn{2}{|l|}{ Black } \\
\hline & Male & Female & Male & Female & Male & Female \\
\hline \multicolumn{7}{|l|}{$16-54$} \\
\hline No & 1156 & 784 & 138 & 99 & 84 & 54 \\
\hline Rate & 49 & 33 & 176 & 125 & 176 & 98 \\
\hline $\begin{array}{l}\text { Relative rate } \\
(95 \% \mathrm{CI})\end{array}$ & $1 \cdot 0$ & $1 \cdot 0$ & $\begin{array}{c}3 \cdot 6 \\
(3-0,4-3)\end{array}$ & $\begin{array}{c}3 \cdot 8 \\
(3-1,4-7)\end{array}$ & $\begin{array}{c}3 \cdot 6 \\
(2-9,4-5)\end{array}$ & $\begin{array}{c}2 \cdot 9 \\
(2-2,3-8)\end{array}$ \\
\hline \multirow{2}{*}{\multicolumn{7}{|c|}{$\begin{array}{l}55-64 \\
\text { No }\end{array}$}} \\
\hline & 646 & 397 & 74 & 51 & 40 & 34 \\
\hline Rate & 143 & 84 & 731 & 701 & 521 & 540 \\
\hline $\begin{array}{l}\text { Relative rate } \\
(95 \% \text { CI })\end{array}$ & $1 \cdot 0$ & $1: 0$ & $\begin{array}{c}5 \cdot 1 \\
(4-0,6-5)\end{array}$ & $\begin{array}{c}8 \cdot 4 \\
(6-3,11-2)\end{array}$ & $(2-6,5-0)$ & $\begin{array}{c}6 \cdot 5 \\
(4-6,9-2)\end{array}$ \\
\hline \multirow{2}{*}{$\begin{array}{l}65+ \\
\text { No } \\
\text { Rate }\end{array}$} & 1261 & 690 & 50 & 28 & 37 & 23 \\
\hline & 211 & 77 & 1083 & 689 & 1019 & 777 \\
\hline \multirow{2}{*}{$\begin{array}{l}\text { Relative rate } \\
(95 \% \mathrm{CI}) \\
\text { All } 16+\end{array}$} & $1 \cdot 0$ & $1 \cdot 0$ & $\begin{array}{c}5 \cdot 1 \\
(3-8,6-8)\end{array}$ & $\begin{array}{l}8 \cdot 9 \\
(6-1,13-0)\end{array}$ & $\begin{array}{c}4 \cdot 8 \\
(3-5,6-7)\end{array}$ & $\begin{array}{l}10 \cdot 1 \\
(6-7,15-3)\end{array}$ \\
\hline & & & 262 & & & \\
\hline Rate & $\begin{array}{r}3003 \\
90\end{array}$ & 50 & 281 & $\begin{array}{l}1 / 8 \\
196\end{array}$ & $\begin{array}{l}101 \\
272\end{array}$ & $\begin{array}{l}111 \\
172\end{array}$ \\
\hline Relative rate & $1 \cdot 0$ & $1 \cdot 0$ & $3 \cdot 1$ & 3.9 & 3.0 & $3 \cdot 4$ \\
\hline$(95 \% \mathrm{CI})$ & & & $(2-7,3-5)$ & $(3-3,4-5)$ & $(2-6,3-5)$ & $(2-8,4-1)$ \\
\hline
\end{tabular}

care has been available for analysis. We examine relative risks in relation to ethnicity and the underlying cause of end-stage renal failure and the issue of geographical access. The implications for the future development of renal services at local and national levels are discussed.

\section{Method}

As part of the national review of renal services in England, data were obtained retrospectively from all of the 53 adult renal units in England on each patient accepted onto the renal replacement programme. The data items included age, sex, ethnicity, underlying disease and place of residence. For the units in the four Thames regions the data were collected as part of the London Implementation group review of renal services for the calendar years 1991 and $1992 ;^{6}$ for the other units data were for the financial years 1991-92 and 1992-93. Very few patients (estimated at under 10), while resident in England were treated in units in Wales or Scotland, no data were included on their characteristics. Patients resident in Wales and Scotland but treated in the English units were excluded. Completeness of the data on acceptances was $99.0 \%$ for age, sex, and district of residence, $93.5 \%$ for ethnicity, and $91.9 \%$ for cause.

Patients were ascribed by their renal units into the following ethnic categories: white, Asian, black, or other. Population denominators for the ethnic populations were taken from the 1991 census. The census categories Indian, Pakistani, and Bangladeshi were aggregated to form the denominator for Asian patients, and black Caribbeans, black Africans, and black others were aggregated to form the denominator for black patients.

The underlaying disease was specified by the renal units using the European Dialysis and Transplant Association (EDTA) coding system. This was only available from renal units other than the Thames regions. For renal units in the Thames regions, patients were only classified as being diabetic or not.

Acceptances were all those adults aged 16 and above resident in England who were ac- cepted onto renal replacement therapy in the two years of the study. Patients who were returning to dialysis after a failed renal transplant were excluded. Average annual age and sex specific crude acceptance rates and relative risks were calculated in relation to ethnic group. Indirectly age standardised ratios were computed in relation to sex, using age (10 year bands) and sex specific rates for England as standard. Cause specific rates and relative risks were computed for each ethnic group. Data of the heterogeneous "other" ethnic group are not presented.

We estimated the geographical variation in renal replacement provision in relation to ethnic group by regional and district health authority using boundaries as at April 1991. We also investigated the possibility that acceptance rates in minority ethnic populations could be influenced by geographical access to services, since most renal units are in urban conurbations which is also where most minority ethnic populations reside. Rates for Asian and black people were therefore compared with those for whites in selected districts, namely those with the largest Asian and black populations, hence controlling for geographical access. Data for the 37 districts each with a combined Asian and black population exceeding 20000 were pooled and acceptance rates and relative risks for ages 16 and over were derived by ethnic group and by age group.

\section{Results}

There were 5901 adult acceptances who had ethnicity coded, of which $86.3 \%$ were white people, $7 \cdot 7 \%$ Asian people, and $4 \cdot 7 \%$ black people. This compares with the 1991 census breakdown in England where $93.8 \%$ of the population were white, $3.0 \%$ Asian, and $1.9 \%$ black. Asian and black people aged 16 and over had threefold higher acceptance rates $(3.5$ and 3.2) for renal replacement therapy compared with white (table 1). Acceptance rates increased with age in all ethnic groups in both sexes. Moreover the relative rates of black and Asian people compared with whites increased with age in both sexes especially among women. After standardising rates for age and sex relative 
Table 2 Age standardised treatment acceptance ratios for adults (age 16+) in relation to ethnic group in England, 1991-92 (England = 100).

\begin{tabular}{|c|c|c|c|}
\hline & \multicolumn{3}{|c|}{ Ratios (No of cases) } \\
\hline & White & Asian & Black \\
\hline $\begin{array}{l}\text { Males } \\
(95 \% \text { CI }) \\
\text { Females } \\
\text { (95\% CI) } \\
\text { Total } \\
95 \% \text { CI }\end{array}$ & $\begin{array}{l}90(3063) \\
(84,97) \\
89(1871) \\
(81,94) \\
90(4934) \\
(85,95)\end{array}$ & $\begin{array}{l}385(262) \\
(247,485) \\
461(178) \\
(337,594) \\
422(440) \\
(348,507)\end{array}$ & $\begin{array}{l}354(161) \\
(253,474) \\
392(111) \\
(260,556) \\
374(272) \\
(290,470)\end{array}$ \\
\hline
\end{tabular}

risks increased to $4 \cdot 2$ in Asian people and $3 \cdot 7$ in black people (table 2) compared with all populations combined.

Rates in relation to the main underlying causes are shown by ethnic group in table 3 . Diabetic status was available for the whole sample. Although both types of diabetes were specified in regions other than the Thames ones, there was mis-specification, as the insulin dependent diabetes mellitus acceptance rate was increased in ethnic minorities as well as that for non-insulin dependent diabetes mellitus. There is, however, no epidemiological evidence for an increase of insulin dependent diabetes millitus in such populations. Overall, $15 \%$ of cases were diabetic. The respective figures in relation to ethnic group were $12 \%$ for white people, $21 \%$ for Asian people, and $25 \%$ for black people. Thus, diabetes was recorded as the underlying cause in almost a quarter of cases in ethnic minority groups. The relative rate for Asian people was $5 \cdot 8$ and that for black people was $6 \cdot 5$, compared with white people.

For the non-Thames regions, notable features were the increases in glomerulonephritis, pyelonephritis, and "unknown" cause in Asian people, and the higher rates of hypertension in black and Asian people (although the number

Table 3 Cause specific relative risks of treatment (age 16+) in relation to ethnic group in England*, 1991-92.

\begin{tabular}{llll}
\hline Cause (EDTA code) & \multicolumn{3}{l}{ Relative risk (no of cases) $(95 \%$ CI) } \\
\cline { 2 - 4 } & White & Asian & Black \\
\hline Diabetes $(80,81)$ & $1 \cdot 0(619)$ & $5 \cdot 8(92)$ & $6 \cdot 5(70)$ \\
& & $(4 \cdot 7,7 \cdot 2)$ & $(5 \cdot 1,8 \cdot 3)$ \\
Hypertension excluding & $1 \cdot 0(234)$ & $2 \cdot 2(10)$ & $3 \cdot 2(6)$ \\
malignant (72) & & $(1 \cdot 2,4 \cdot 1)$ & $(1 \cdot 4,7 \cdot 2)$ \\
Malignant & $1 \cdot 0(48)$ & $3 \cdot 2(3)$ & $7 \cdot 8(3)$ \\
hypertension (71) & & $(1 \cdot 0,10 \cdot 3)$ & $(2 \cdot 4,25 \cdot 0)$ \\
Other renovascular & $1 \cdot 0(162)$ & $1 \cdot 3(4)$ & $3 \cdot 1(4)$ \\
(70,79) & & $(0 \cdot 5,3 \cdot 5)$ & $(1 \cdot 1,8 \cdot 4)$ \\
Glomerulonephritis & $1 \cdot 0(498)$ & $2 \cdot 8(27)$ & $2 \cdot 3(9)$ \\
(10-19) & & $(1 \cdot 9,4 \cdot 1)$ & $(1 \cdot 1,4 \cdot 4)$ \\
Pyelelonephritis & $1 \cdot 0(424)$ & $2 \cdot 7(22)$ & $1 \cdot 2(4)$ \\
(20-29) & & $(1 \cdot 8,4 \cdot 1)$ & $(0 \cdot 4,3 \cdot 2)$ \\
Polycystic kidney & $1 \cdot 0(258)$ & $1 \cdot 4(7)$ & $1 \cdot 9(4)$ \\
(41) & & $(0 \cdot 7,3 \cdot 0)$ & $(0 \cdot 7,5 \cdot 1)$ \\
Unknown (00) & $1 \cdot 0(694)$ & $5 \cdot 7(77)$ & $1 \cdot 8(10)$ \\
& & $(4 \cdot 5,7 \cdot 2)$ & $(1 \cdot 0,3 \cdot 4)$ \\
\hline
\end{tabular}

* The data for diabetes relate to England, data for all other causes to the non-Thames regions only.

tOther causes not presented interstitial nephritis (30-39), other cystic kidney (40-49), heredity disease (50-66), polyarteritis, Wegener's granulomatosis, systemic causes (82-89) and "other" (96-99).

Table 4 Age standardised acceptance ratios for treatment (age 16+) in relation to ethnic group in 37 district health authorities with the largest combined Asian and black populations, 1991-92. All 37 district health authorities $=100$.

\begin{tabular}{llll}
\hline & White & Asian & Black \\
\hline No of cases & 1298 & 311 & 232 \\
Ratio (95\% CI) & $78(70,87)$ & $290(230,360)$ & $289(220,371)$ \\
\hline
\end{tabular}

of cases was small in both). In absolute terms, diabetes was the most important cause in Asian and black people, with "unknown" cause glomerulonephritis and pyelonephritis also significant in Asian people. Systemic lupus was reported in five patients, one of whom was one black, and renal tuberculosis in two, neither was Asian.

Although Asian and black minority ethnic populations comprise $5 \%$ of the populaton of England, $13 \%$ of new acceptances for renal replacement therapy were from these groups. In some regions the proportions were much higher: $27 \%$ in North West Thames, $24 \%$ in North East Thames, and $19 \%$ in the West Midlands. (The Yorkshire and North Western data were incomplete due to two units being unable to provide any ethnic coding). In 18 districts over $20 \%$ of patients were Asian, and in nine over $20 \%$ were black. In total, in 19 of 178 districts over $30 \%$ of new patients were of minority ethnic origin.

We investigated the possibility that increased acceptance rates in minority ethnic populations compared with whites could reflect closer proximity to services by comparing ethnic rates with those for white people in a pooled group of 37 districts with large black and Asian populations. Whites and ethnic minority groups living in the same area would have similar geographical access, and hence, from that perspective, would be expected to have similar acceptance rates. In fact, relative rates were still high for Asian and black people compared with whites (table 4) and there was an increase in the relative rate in relation to age in both ethnic populations, although it was less marked than in England as a whole.

\section{Discussion}

This paper provides for the first time a comprehensive analysis of recent national data on the ethnic determinants of acceptance onto renal replacement therapy. We show that the "met need" for end-stage renal failure by renal replacement therapy is increased in Asian and black populations compared with whites and that the relative risks increase with age in both populations. The excess over whites is greater in minority ethnic women than in men, although in all ethnic groups male rates exceed female rates. There are specific underlying causes which contribute to these increases and in some health authorities the ethnic dimension is a major component in renal placement therapy provision.

Previous work has shown the higher, acceptance rates among Asian and black people. Studies in the US have shown that black people have increased acceptance rates onto the Medicare funded programme compared with whites. ${ }^{8-10}$ The latest report of the US renal data for the period 1988-90 found a similar 3.9 fold increase in black acceptances, although the relative rate decreased with age. ${ }^{10}$ The London Implementation Group reported threefold increases in crude acceptances among black and Asian people compared with whites in the 
four Thames regions but it did not examine data in the detail presented here. ${ }^{67}$

These data indicate met need rather than the true underlying population need, which can only be ascertained from population based surveys of the incidence of end-stage renal failure in areas with a high concentration of ethnic minority populations and consideration of the proportion in whom renal replacement therapy would be appropriate. Nevertheless, it is important to analyse why the acceptance rates are increased in Asian and black people. There are five main possibilities:

- Numerator and/or denominator inaccuracies;

- True increase in incidence and prevalence of underlying diseases;

- Genetic or environmental susceptibility to progression to nephropathy;

- Higher referral for treatment because ethnic minority populations generally live closer to renal units;

- Reduced access to preventive health care that might reduce the progression of underlying diseases.

Ethnic coding was complete in over $90 \%$ of cases. As there is no evidence of selective undercoding in relation to ethnic group (the missing data were clustered in a few units with mixed local populations), uncoded cases would increase absolute rates but relative rates would remain relatively unchanged. Ethnicity was ascribed by the renal units and any inaccuracies in coding are likely to have had non-differential effects. Disease coding data were incomplete. Missing data were again clustered in a few units in areas with varying compositions of ethnic minority populations and so this again would not introduce a selective bias to the results.

Ethnic rates will be overestimated if there was selective underenumeration by ethnic group in the 1991 census. There is some evidence for underenumeration in young black males but the estimated magnitude is unlikely to effect the results significantly. ${ }^{11} 12$

The underlying prevalence of some diseases known to be major causes of end-stage renal failure are increased in these populations. Studies in Britain have shown that the prevalence of non-insulin dependent diabetes mellitus among Asian people is more than four times greater than among whites. ${ }^{13-15}$ This is true of all Asian subgroups despite variation in cultural and socioeconomic factors. Twenty per cent of Asians aged 40-69 are diabetic, by 65 the proportion is a third. Mortality rates from diabetes in Asian born people in this country are three times higher than the national rate. ${ }^{16}$ In Leicester the rate of acceptance for diabetic nephropathy was increased 10 fold among Asians compared with whites, the excess risk being confined to patients with non-insulin dependent diabetes mellitus. ${ }^{17}$ Asians are also at increased risk of hypertension. In this study we showed significantly increased rates of acceptance for diabetics among Asian and a small excess of hypertension. There were also excess rates for glomerulonephritis and pyelo- nephritis, but very striking was the increase in "unknown causes".

There have been three retrospective studies based on patients accepted in renal units which have compared the underlying cause by ethnic group. ${ }^{18-20}$ In the West Midlands Asian people had a significant excess of hypertension/renovascular disease and renal tuberculosis and a non-significant excess of "unknown" cause compared with whites. ${ }^{18}$ In London and Leicester studies showed an excess of diabetes and unknown causes in Asians; one also found an excess of glomerulonephritis and pyelonephritis. ${ }^{1920}$ The latter study showed that unknown cause (in which patients often present late with small smooth shrunken kidneys and biopsy is not performed) was commoner in female Asians and there was an association with active non-renal tuberculosis. The authors suggest that such renal disease could be due to tubercular interstitial nephritis. We were unable to study further our cases of "unknown cause" to confirm or refute this finding and this remains a question for further research.

Black populations in the UK have a higher risk of hypertensive disease. Caribbean born people, for example, have a fivefold excess risk of mortality from hypertensive disease and a twofold excess from hypertension related diseases such as stroke. ${ }^{16}$ They also have a markedly higher prevalence of non-insulin dependent diabetes mellitus, with mortality two to four times the national rate. ${ }^{16}$ The US acceptance studies have shown excess in all disease categories, except polycystic kidney disease, and risk is especially increased for hypertensive end-stage renal failure, ${ }^{8-10}$ although there is some evidence to suggest over ascertainment of this cause. Age-sex adjusted relative rates were 6.2 for hypertensive endstage renal failure and 3.8 for diabetic endstage renal failure in the latest US national data. ${ }^{10}$ The West Midlands study found a significant excess of hypertension/renovascular disease, diabetes, and systemic lupus erythematosis in black people compared with whites, ${ }^{18}$ and a London study noted an excess proportion of hypertensive endstage renal failure. $^{20}$

Does susceptibiity of developing nephropathy influence the incidence of end-stage renal failure over and above the incidence of the underlying conditions? Several population based ecological studies in the US have attempted to correct the increased rates of endstage renal failure for underlying prevalence and severity of the predisposing conditions. McLellan found that hypertensive end-stage renal failure rates in black people in Georgia were still increased after adjustment for the prevalence of hypertension. ${ }^{21}$ Crude rates were increased 8.4 fold, age-sex adjusted rates 11.3 , and age-sex hypertension adjusted rates $5 \cdot 7$, and there was no evidence that differences in blood pressure control could account for these differences. ${ }^{21}$ They postulated that increased susceptibility to end-stage renal failure or a less likely explanation, erroneous classification of hypertensive end-stage renal failure, explained the findings. There is some evidence of racial 
differences in the response of kidneys to hypertension, ${ }^{22}$ and another US study failed to show that the excess of hypertensive end-stage renal failure in blacks was due to prevalence, severity, or age at onset of hypertension, or to diabetes or socio-economic status. ${ }^{23}$ Similar work has been conducted to explain the excess of diabetic end-stage renal failure in black people. ${ }^{2425}$ Brancati showed that in Maryland the excess of diabetes mellitus related end-stage renal failure in black people was not explained by the higher prevalence of diabetes or hypertension or differences in age, socioeconomic status, or access to health care (defined as no regular income source or no insurance).$^{24}$ The study in Leicester cited above found that the excess acceptance rate in Asians was even higher among diabetics than in the general population. ${ }^{17}$ This suggests that Asians are more susceptible to diabetic nephropathy ${ }^{2627}$ and/or that preventive care was poorer. There is no information on the latter case in the UK.

Could excess rates be due to greater referral, as most ethnic minority populations live closer to renal units? Such supply factors are known to influence specialist services which are centralised in urban areas. ${ }^{28}$ However, the evidence of excess in different areas in the US and UK, the excess risk in 16-54 year olds who are most likely to be accepted wherever they live, and the correlation at district level between the acceptance rate and ethnic minority population found in the Thames study ${ }^{7}$ suggest this is not a major factor. In this study, the ethnic relative rates were raised even when only areas with high ethnic minority populations were studied - that is, in which the comparison white population lived within the same area. Further work is, however, required to explore in depth the relative contributions of need, access, and supply to acceptance onto renal replacement therapy. The question of whether there is reduced access to or effectiveness of preventive health care among ethnic minorities is an unexplored issue which needs further study. This might be particularly relevant to explaining the high relative rates in females in both ethnic minority groups.

These findings have several important implications for the future provision of renal services in the UK. Firstly, overall national population need in the UK will be higher than the estimate of 80 pmp. ${ }^{5}$ For example if a relative need for Asian and black people of three times that of whites is assumed, the population need is about $86 \mathrm{pmp}$ for the UK as a whole based on the ethnic proportions in the 1991 census. It will be considerably higher in districts with large ethnic minority populations. However, this does not take into account the younger age structure of these populations compared to the demographically more mature white population. Relative need will increase as ethnic minority populations age, and this will be disproportionate as this study suggests that the relative risks rise with age. The caveat to this is whether younger generations of ethnic minority populations carry the same lifetime risks as the first generation. Projection of demographic trends in ethnic minorities will begin to reveal the impact of the ageing of ethnic minorities on need for renal replacement therapy.

Modelling work undertaken for the national renal review based on development of Wood's Manchester model ${ }^{29}$ estimated the steady state position of renal replacement therapy stock at which the numbers taken onto renal replacement therapy equal those dying or withdrawing. Even at current acceptance rates, the stock is projected to increase by over $50 \%$, but at intakes approaching $90 \mathrm{pmp}$ the steady state stock doubles. Preventive measures to reduce the need for renal replacement therapy in high risk populations are therefore imperative and require further development. For example, strategies for diabetes mellitus include primary prevention, secondary prevention by control of hypertension, and tertiary prevention by protein restriction and early treatment of infection.

What are the research implications? There is need for a population based estimation of the incidence of end-stage renal failure in ethnic minorities from which a true estimate of need can be derived. From this an assessment of the equity of provision of renal replacement therapy for ethnic minorities could then be made. Further studies are needed to determine whether these populations are more susceptible to kidney damage from underlying diabetes or hypertension. If increased susceptibility is found so the need for primary and secondary preventive efforts will be even more urgent. The pathogenesis of the "unknown cause" group in Asians requires elucidation.

We thank all the renal unit staff who contributed data to these two reviews, staff at the Institute of Public Health, University of Surrey for data analysis and Professor M McGeown and M I Jones for advice on the Thames study. The National Renal Review was funded by the Department of Health.

1 Stevens A, Gabbay J. Needs assessment, needs assessment. Health Trends 1991;32:20-3.

2 Feest TG, Mistry CD, Grimes DS. Mallick NP. Incidence of advanced chronic renal failure and the need for endstage replacement treatment. $B M F$ 1990;301:897-900.

3 McGeown MG. Prevalence of advanced renal failure in Northern Ireland. $B M \mathcal{F}$ 1990;301:900-3.

4 Khan IH, Catto GRD, Edward N, McLeod AM. Chronic renal failure: factors influencing nephrology referral. $Q \mathcal{F}$ Med 1994;87:559-64.

5 Renal Association. The provision of services for adult patients with renal disease in the United Kingdom. London: Renal Association, 1991.

6 London Renal Services Review Group. Report of an independent review of specialist services in London. Renal. Londependent review of spec

7 Roderick PJ, Jones I, Raleigh VS, McGeown M, Mallick N. Population need for renal replacement therapy in Thames regions: ethnic dimension. BMF 1994;309:1111-

8 Rostand SG, Kirk K, Rutsky E, Pate B. Racial differences in the incidence of treatment of end-stage renal disease. $N$ Engl F Med 1982;306:1276-9.

9 Hiatt RA, Friedman DG. Characteristics of patients referred for treatment of endstage renal disease in a defined population. Am $\mathcal{F}$ Public Health 1982;72:829-33.

10 United States Renal Data Systems. 1993 Annual data report. Bethesda, MA. US Department of Health and Human Services, 1993

11 Soni Raleigh V, Balarajan R. Public health and the 1991 Census. Non-random underenumeration complicates interpretation. BMF 1994;309:287-8.

12 Glover GR. Sex ratio errors in census data. $B M \mathcal{F} 1993 ; 37$

13 Mather HW, Keen $\mathrm{H}$. The Southall diabetes survey; the prevalence of known diabetes in Asians and Europeans. prevalence of known diabe

14 Simmons D, Williams DRR, Powell MJ. Prevalence of diabetes in a predominantly Asian community: preliminary diabetes in a predominantly Asian community: preliminary findings 21 .

15 McKeigue PM, Shah B, Marmot MG. Relation of central obesity and insulin resistance with high diabetes prevalence and cardiovascular risk in South Asians. Lancet 1991:337 $382-6$. 
16 Balarajan R, Bulusu L. Mortality among migrants in England and Wales, 1979-83. In: Britton M ed. Mortality and geography: a review in the mid-1980s, England and Wales. OPCS Series DS no 9, 103-21 (see appendix tables). London: HMSO, 1990

17 Burden AC, McNally P, Feehally K, Walls J. Increased incidence of end stage renal failure secondary to diabetes mellitus in Asian ethnic groups in the United Kingdom. Diabet Med 1992;9:641-5.

18 Clark TJ, Richards NT, Adu D, Michael J. Increased prevalence of dialysis dependent renal failure in ethnic minorities in the West Midlands. Nephrol Dial Transplant 1993;8:146-8.

19 Pazianas M, Eastwood J, MacRae K, Phillips M. Racial origin and primary renal diagnosis in 771 patients with end stage renal disease. Nephrol Dial Transplant 1991;6: 931-5.

20 Lightstone L, Rees AJ, Tomson C, Walls J, Winnearls CJ, Feehally J. High incidence of endstage renal disease in Asians in the UK. $Q \mathcal{F}$ Med 1995;88(3):167-73.

21 McLellan W, Tuttle E, Issa A. Racial differences in the incidence of hypertensive end stage renal disease (ERSD) are not entirely explained by differences in the prevalence of hypertension. Am F Kid Dis 1988;4:285-90.
22 Shulman NB, Dallas Hall W. Renal vascular disease in African-Americans and other racial minorities. Circulation 1991;83:1487-9.

23 Whittle JC, Whelton PK, Seidler A, Klag M. Does racial variation in risk factors explain black-white differences in the incidence of hypertensive end-stage renal disease. Arch Intern Med 1991;151:1359-64.

24 Brancati F, Whittle J, Welton P, Seidler A, Klag M. The excess incidence of diabetic end stage renal disease among excess incidence of diabetic end stage renal disease among
blacks. $¥ A M A$ 1992;268:3079-84.

25 Cowie CC, Port FK, Wolfe RA, Savage PJ, Hawthorne VM. Disparities between incidence of diabetic end stage rena disease by diabetic type. Diabetes 1990;321:1074-9.

26 Allawi J, Rao PV, Gilbert R et al. Microalbuminuria in noninsulin dependent diabetics: its prevalence in Indian as compared with Europid patients. BMF 1988;296:462-4.

27 Samanta A, Burden AC, Feehally J, Walls J. Diabetic renal disease: differences between Asians and white patients. BMF 1986;293:366-7.

28 Dalziel $M$, Garrett C. Intraregional variation in the treatment of end-stage renal failure. BM7 1987;294:1382-3.

29 Wood IT Mallick NP, Wing AJ Prediction of re needed to achieve the national target for treatment of renal failure. $B M \mathcal{F}$ 1987;294:1467-70. 